Journal of Money and Economy

Vol. 15, No. 3, Summer 2020

pp. 343-356

DOI: $10.29252 /$ jme.15.3.343

Original Research Article

\title{
Volatility Spillover of the Exchange Rate and the Global Economy on Iran Stock Market
}

\begin{abstract}
Ahmad Gholami*
Ehsan Salami ${ }^{\dagger}$

Received: 10 Jul 2020

Approved: 6 Feb 2021

Financial markets are one of the most fundamental markets in any country. In the financial markets, the securities market and the foreign exchange market are sensitive sectors. These two markets are affected by fluctuations and economic cycles, so reflect economic changes rapidly. Changes in the returns of one market due to arbitrage conditions during time lead to changes in the performances of other markets. This paper by dividing the spillover effect into two parts, mean effect and volatility effect, employing DCC-GARCH method, aimed to capture the spillover effects of dollar return, global market, and Iran financial market in the period 1394-1398. Mean conditional results show that stock returns react negatively to dollar returns. In other words, there is a substitution between dollar returns and stock returns among economic agents. For the global economy, the stock market returns decrease with the fluctuations of the global economy index. Still, for the dollar, the relationship is reversed, so that increase in the global economy index volatility increases the dollar return. For the volatility spillover, the results also supported substantial spillover between each market pairs.
\end{abstract}

Keywords: Volatility Spillover, Iran Stock Market, Global Economy, Dynamic Conditional Correlation.

JEL Classification: C58, G15

\section{Introduction}

Nowadays, the capital market reacts quickly to domestic and foreign information, which can be due to the improvement of technology and the expansion of financial instruments. According to the principle of arbitrage, changing in the efficiency of any market causes changes in the efficiency of other markets, which is called mean spillover. Moreover, once the fluctuation in returns has started takes some time for it to decelerate, which is called volatility spillover. Since the behavior of financial instruments affects the

\footnotetext{
*Iran; ahmad.gholami39@gmail.com

† Maybod University, Maybod, Iran; salimi@ meybod.ac.ir
} 
decisions of shareholders and policymakers, it is vital to examine the impact of spillover between the financial instruments in the market.

In the literature, economists to capture interdependence between financial markets usually focus on volatility rather than mean spillover, which generally handled by examining the causality test and dynamic correlation. While the causality shows the path of the spillover, and the correlation test examines the existence of this effect.

Many studies have examined the spillover between exchange rates and financial markets. Along with globalization, financial markets integration has become more important and investigating global crises, and its impact on financial markets is crucial. In recent years, given the conditions of sanctions, it may be thought that changes in the global market will not affect the domestic economy. The lack of studies on the fluctuations of financial markets intensifies the need for thorough research in this area. In this article, the spillover effect is divided into two parts, mean spillover effect and volatility spillover effects, and both for the Iran stock market are examined. For this purpose, based on daily data of exchange rate, stock price index, and global market index and using GARCH family models, spillover effects of global market and exchange return on the financial market examined. The remainder of this paper organized as follows. Section 2 reviews literature, section 3 introduce the methodology, section 4 submits estimation results, and section 5 present conclusions.

\section{Literature Reviews}

Numerous studies in different countries have examined the spillover effect on stock prices. In the past, these studies have been based on Granger's causality test (1969) and autoregressive models of Sims (1980). Recently, multivariate GARCH models have generally been preferred. For example, Sun and Zhang (2009) used univariate and multivariate heteroscedasticity models to examine the impact of the U.S. financial market spillover on the Chinese and Hong Kong stock markets. The results of this study confirm the spillover of U.S. financial market fluctuations on the stock prices of the two countries.

Kang et al. (2017), using data from nine countries, Brazil, China, Indonesia, Korea, Malaysia, Philippines, Russia, South Africa, and Thailand from 2005 to 2016, examined the spillover effect between emerging countries. They concluded the global financial crisis spillover has increased. Also, investigating volatility spillover between the foreign exchange market and the stock market, confirmed the spillover effect during market turmoil. 
Raghavan and Dark (2008) used the bivariate GARCH model to examine the spillover effect of dollar volatility on the Australian stock price index. Using the daily data for 1995-2004, they found that there was a one-way volatility spillover of the exchange rate on the price index.

Ely (2015), by applying a multivariate GARCH model for Daily Data 1999-2014, inspected volatility spillover, and mean spillover between the stock market and exchange market in Brazil. He reported that money market movements affected both volatility and the return of the money market.

Diebold and Yilmaz (2012) examined spillover for four U.S. markets, including stock markets, bonds, currency, and commodities. The results have shown that after financial crises, volatility spillover of the stock market to other markets is essential.

Bozma and Başar (2018) analyzed volatility spillover among the stock markets of Turkey, Romania, Poland, Hungary, and Ukraine using a multivariate GARCH model for daily data for 2011-2016. They concluded that the Turkish stock market was affected not only by its volatility but also by volatility in the Hungarian and Polish stock markets.

Vardar, Aksoy, and Can (2008) used the GARCH model for daily data for 2001-2008 to examine the effect of interest and exchange rate movements on the stock market. The findings suggest that exchange rates, in addition to technology, increase volatility in other sectors.

Taghavi and Biabani (2003), by employing the autoregressive model of moving average accumulation, have investigated the effect of exchange rate changes on stock returns. They have reached a significant relationship between the two markets. The results also show that stocks that have higher liquidity have a greater impact.

Nahidi and Nikbakht (2010) have used the autoregressive model for conditional heteroscedasticity to investigate the effect of exchange rate instability on the cash profit and price index of the Tehran Stock Exchange. The results indicate that there is a positive relationship between the mentioned variables so that the increase of instability in the real exchange rate results in the rise in the cash profit index and the price index of the Tehran Stock Exchange.

Shojaei et al. (2011) used the autoregressive model for conditional heteroscedasticity of two regimes to investigate the effect of currency market shocks on the Tehran Stock Exchange index. Results show that the Tehran Stock Exchange index was affected by the shocks of the foreign exchange market, but it did not change during boom periods. 
Heidari and Bashiri (2012), using the autoregressive model for conditional heteroscedasticity, have examined the relationship between exchange rate uncertainty and Tehran Stock Exchange index. The results indicate a significant relationship between exchange rate uncertainty and the total index value.

Abounoori, et al. (2013) have assessed the dynamics of the relationship between the exchange rate and stock index of the Tehran Stock Exchange using the GARCH model from July 1992 to July 2010. The results showed that there was no significant long-term relationship between the effective real exchange rate and the stock price. Besides, after examining the effect of fluctuations between the foreign exchange market and the stock market, they concluded that both variables are directly and indirectly affected by their fluctuations. Still, none of these markets have had a significant impact on the other market.

Botshekan et al. (1396), using four well-known multivariate GARCH models in the period 1385-1395, examined the conditional correlation and volatility spillover of gold, oil, housing, and foreign exchange market on the stock exchange. The results confirmed volatility spillover among stock, foreign exchange, gold, and the oil market while this relationship with the housing market is not confirmed.

\section{Methodology}

Well-known models of volatility are GARCH models were introduced by Engle (1982) and Bollerslev (1986). The success of these models has led to the formation of a family of univariate and multivariate GARCH models that examine the different behaviors of financial markets. Engle and Kroner (1995) defined a set of multivariate GARCH models. The most famous are the diagonal VECH and BEKK models. But at the same time, these models have shortcomings. The VECH model lacks correlation among variances, and the BEKK model is difficult to estimate through the maximum likelihood function when it has more than two variables. These problems lead to follow other models, such as the CCC model. However, the assumption of conditional correlation stability in this model was unrealistic and led to the formation of the DCC model. This model assuming the volatilities change over time, is a tool for predicting and analyzing the fluctuations of time series. The idea of this model is that the covariance matrix is a combination of the standard conditional deviation $\left(D_{t}\right)$ and the correlation matrix $\left(R_{t}\right)$. In this model, $\left(D_{t}\right)$ and $\left(R_{t}\right)$ are designed to change over time. The DCC model is defined as follows: 
$r_{t}=\mu_{t}+\sum_{s=1}^{p} \emptyset_{s} r_{t-s}+\epsilon_{t}$

$\epsilon_{t} \sim N\left(0, H_{t}\right)$

$H_{t}=D_{t} R_{t} D_{t}$

$\left[\begin{array}{l}r s_{t} \\ r_{d_{t}}\end{array}\right]=\left[\begin{array}{l}\mu_{r s} \\ \mu_{r_{d}}\end{array}\right]+\sum_{s=1}^{p}\left[\begin{array}{ll}\varphi_{11} & \varphi_{12} \\ \varphi_{21} & \varphi_{22}\end{array}\right]\left[\begin{array}{l}r s_{t-1} \\ r_{d_{t-1}}\end{array}\right]+\left[\begin{array}{l}\epsilon r s_{t} \\ \epsilon r d_{t}\end{array}\right]$

$r_{t}$ is the vector of return on assets at time $\mathrm{t}$

$\mu_{t}$ is a vector of the expected value of $r_{t}$

$H_{t}$ is the conditional variance matrix $\epsilon_{t}$

$R_{t}$ is the conditional correlation matrix $\epsilon_{t}$

and $D_{t}$ is the diagonal matrix of the standard dynamic errors obtained from the single variable GARCH model as follows

$D_{t}=\operatorname{diag}\left(\sqrt{h r s_{t}}, \sqrt{\mathrm{hrd}}\right)$

And $\mathrm{h}$ is defined as a univariate GARCH model.

$h_{i t}=w_{i}+\alpha_{i} \epsilon_{i t-1}^{2}+\beta_{i} h_{i t-1}$

The DCC model is estimated in two steps. In the first step, the univariate GARCH model is estimated and in the second step, the standard errors resulting from the first step $\left(\eta_{i t}=r_{i t} / \sqrt{h_{i t}}\right)$ are used to estimate the model. The model is specified as follows:

$R_{t}=\operatorname{diag}\left(q_{11 . t}^{-1 / 2} \ldots . q_{22 . t}^{-1 / 2}\right) Q_{t} \operatorname{diag}\left(q_{11 . t}^{-1 / 2} \ldots . q_{22 . t}^{-1 / 2}\right)$

$Q_{t}$ is a definite and symmetric positive matrix and is assumed to have the following GARH pattern:

$Q_{t}=\left(1-\theta_{1}\right) \bar{Q}+\theta_{1} \eta_{t-1} \eta_{t-1}^{\prime}$

parameter $\theta_{1}$ is scalar and shows the effects of past shocks and dynamic correlation on current correlation and $Q_{t}$ is an unconditional variance matrix of standardized errors.

It can be said that DCC models create a space for more flexibility in specifying the GARCH models in the variance section. Since conditional variances (along with conditional mean) can be estimated using the univariate $\mathrm{N}$ model, DCC models can be developed into a variety of complex GARCH models. The maximum likelihood function used to estimate GARCH models because the stability of estimators of this method has been proven. Bollerslev 
and Wooldridge (1992) confirmed that even if the assumption of normality is violated, the use of this method does not affect the accuracy of standard errors.

In this study, several proxies have been used. For dollar price index, close price in the open market used, and the data is taken from the central bank's database. The total stock index has been used for the stock price index, and the relevant data have been adapted from the database of the Tehran Stock Exchange Organization. All data are daily from 26/03/1394 to 28/12/1398. The Global Volatility Index (VIX) used to examine global development, which is introduced as an explanatory variable in the model and data obtained from the Rutters database. The formula $\ln \frac{p_{t}}{p_{t-1}}$ used to produce return series.. Figure 1 shows a comparison between real data and returns.
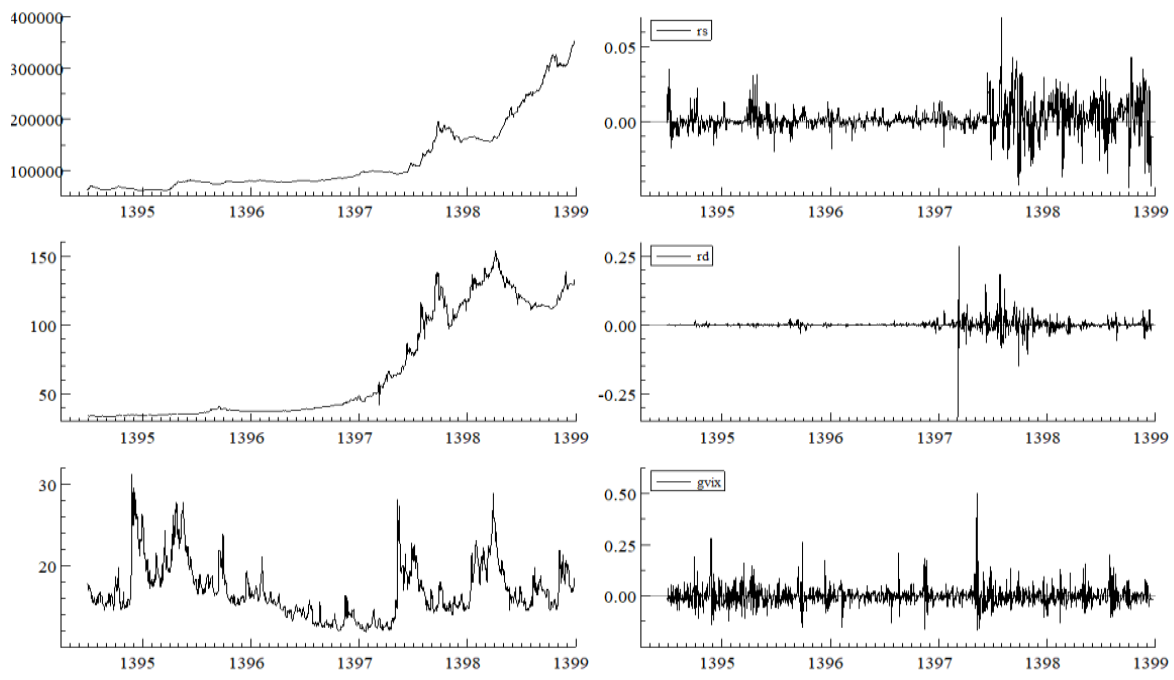

Figure 1. Comparison between Real Data and Their Returns.

\subsection{Descriptive Statistics}

Table 1 describes the data used in the study. In panel A (Table 1), for each return series, the mean value is close to zero. For each return series, the standard deviation is larger than the mean value. Each return series displays a small amount of skewness, and a large amount of kurtosis and the returns are not normally distributed. In panel B (Table 1), unconditional correlation coefficients in stock market index returns indicate pairwise correlations. The correlation between $\boldsymbol{r} \boldsymbol{S}$ and $\boldsymbol{r} \boldsymbol{d}$ is positive and the correlation between $\boldsymbol{r} \boldsymbol{s}$ and 
$g_{v i x}$ is negative. These results clearly show the inconsistency of the variance and the accumulation of volatility in the data. Thus it confirms application of the GARCH model to examine the relationship between the data.

Table 1

Descriptive statistics of stock market returns.

\begin{tabular}{|c|c|c|c|c|c|c|c|c|c|c|}
\hline Data & Symbol & Mean & Median & Minimum & Maximum & std dev & skewness & Kurtosis & J.B. Test \\
\hline \multicolumn{8}{|c|}{ Panel A- Foreign Exchange Market } \\
\hline Dollar/Rial & $r d$ & 0.002 & 0.00 & -0.33 & 0.29 & 0.0215 & -0.4933 & 86.86 & $360243^{*}$ \\
\hline \multicolumn{8}{|c|}{ Stock Market } \\
\hline Stock Index & $r s$ & 0.0003 & 0.006 & -0.04 & 0.07 & 0.0101 & 0.409 & 5.347 & $316.3^{*}$ \\
\hline \multicolumn{8}{|c|}{ Global Market } \\
\hline VIX & $g_{\text {vix }}$ & 0.0002 & 0.0002 & -0.017 & 0.5 & 0.0476 & 1.7767 & \multirow{2}{*}{14.24} & \multirow{2}{*}{$7123^{*}$} \\
\hline \multicolumn{8}{|c|}{ Panel B- Unconditional correlation matrix } \\
\hline rs & $r s$ & $r d$ & $g_{\text {vix }}$ & & \\
\hline rd & 1 & 0.0261 & -0.0651 & \\
\hline$g_{\text {vix }}$ & & 1 & 0.0148 \\
\hline
\end{tabular}

Table 2 shows the results of the stationary test using two Augmented Dicky Fuller (ADF) and Phillips-Peron (P.P.) methods. The results showed that the return series are stationary at the significance level of $1 \%$.

Table 2

The results of stationary tests

\begin{tabular}{|l|l|l|l|l|l|l|}
\hline \multirow{2}{*}{ market returns } & \multicolumn{2}{|l|}{ test ADF } & Phillips-Perron test \\
\cline { 2 - 7 } & non & constant & $\begin{array}{l}\text { Constant } \\
\text { \&trend }\end{array}$ & non & Constant & $\begin{array}{l}\text { Constant } \\
\text { \&trend }\end{array}$ \\
\hline Foreign Exchange Market & $-30.57^{*}$ & $-30.252^{*}$ & $-30.305^{*}$ & $-43.86^{*}$ & $-43.76^{*}$ & $-44.2^{*}$ \\
\hline$r d$ & $-12.47^{*}$ & $-12.72^{*}$ & $-12.87^{*}$ & $-22.85^{*}$ & $-22.87^{*}$ & $-22.88^{*}$ \\
\hline Stock Market & $-25.39^{*}$ & $-25.37^{*}$ & $-25.36^{*}$ & $-34.35^{*}$ & $-34.33^{*}$ & $-34.31^{*}$ \\
\hline$r s$ &
\end{tabular}

* shows significance at $1 \%$

\section{Estimation Results}

The model specification consists of two parts. To investigate the effect of the volatility spillover effect, first, the ARCH effect on the error components be 
examined. Therefore, in the first step, the return on assets is estimated in the form of a VAR model. The number of three lags was selected based on Akaike and Schwartz's criteria. The variable for global returns is considered to be exogenous.

$r s_{t}=c_{10}+\gamma_{11} r s_{t-1}+\gamma_{12} r s_{t-2}+\gamma_{13} r s_{t-3}+\gamma_{14} r d_{t-1}+\gamma_{15} r d_{t-2}+$ $\gamma_{16} r d_{t-3}+\gamma_{17} g_{v i x}$

$r_{d / r_{t}}=c_{20}+\gamma_{21} r s_{t-1}+\gamma_{22} r s_{t-2}+\gamma_{23} r s_{t-3}+\gamma_{24} r d_{t-1}+\gamma_{25} r d_{t-2}+$ $\gamma_{26} r d_{t-3}+\gamma_{27} g_{v i x}$

Estimation results are reported in Table 3. As the ARCH test statistics show, the null hypothesis of no ARCH effect in both models is rejected, so a multivariate GARCH model used in the second step.

Table 3

VAR Model Estimation Results

\begin{tabular}{|c|c|c|c|}
\hline Depended variable & $r s$ & & $r d$ \\
\hline Coefficient & Equation() & & Equation() \\
\hline$c_{10}$ & $\begin{array}{l}0.00055^{*} \\
(0.00027) \\
\end{array}$ & $c_{20}$ & $\begin{array}{c}0.00179 * \\
(0.00072) \\
\end{array}$ \\
\hline$r s_{t-1}\left(\gamma_{11}\right)$ & $\begin{array}{l}0.3832^{*} \\
(0.3118) \\
\end{array}$ & $r s_{t-1}\left(\gamma_{21}\right)$ & $\begin{array}{l}0.01879 \\
(0.0843) \\
\end{array}$ \\
\hline$r s_{t-2}\left(\gamma_{12}\right)$ & $\begin{array}{l}-0.1429^{*} \\
(0.0332) \\
\end{array}$ & $r s_{t-2}\left(\gamma_{22}\right)$ & $\begin{array}{l}0.1862^{*} \\
(0.0898) \\
\end{array}$ \\
\hline$r s_{t-3}\left(\gamma_{13}\right)$ & $\begin{array}{l}0.2535^{*} \\
(0.0311) \\
\end{array}$ & $r s_{t-3}\left(\gamma_{23}\right)$ & $\begin{array}{l}-0.342^{*} \\
(0.0841) \\
\end{array}$ \\
\hline$r d_{t-1}\left(\gamma_{14}\right)$ & $\begin{array}{c}0.0161 \\
(0.0118) \\
\end{array}$ & $r d_{t-1}\left(\gamma_{24}\right)$ & $\begin{array}{l}-0.298^{*} \\
(0.0321) \\
\end{array}$ \\
\hline$r d_{t-2}\left(\gamma_{15}\right)$ & $\begin{array}{c}-0.33^{*} \\
(0.0122) \\
\end{array}$ & $r d_{t-2}\left(\gamma_{25}\right)$ & $\begin{array}{c}-0.1693 * \\
(0.0332) \\
\end{array}$ \\
\hline$r d_{t-3}\left(\gamma_{16}\right)$ & $\begin{array}{c}0.0025 \\
(0.0119)\end{array}$ & $r d_{t-3}\left(\gamma_{26}\right)$ & $\begin{array}{c}0.00179 \\
(0.00072)\end{array}$ \\
\hline$g_{v i x}\left(\gamma_{17}\right)$ & $\begin{array}{l}-0.0119^{*} \\
(0.00536)\end{array}$ & $g_{v i x}\left(\gamma_{27}\right)$ & $\begin{array}{c}0.00146^{*} \\
(0.0145)\end{array}$ \\
\hline \multicolumn{4}{|c|}{ DIAGNOSTICS } \\
\hline $\mathrm{Q}(12)$ & 26.48 & & 39.91 \\
\hline $\mathrm{ADj} \cdot R^{2}$ & 0.1955 & & 0.11 \\
\hline F-STAT & 34.37 & & 16.33 \\
\hline AIC & -6.79 & & -4.81 \\
\hline ARCH TEST & 46.109 & & $141.16^{*}$ \\
\hline J.B. Test & 652.12* & & $8756^{*}$ \\
\hline LogL. & 38.2 & & 2889 \\
\hline
\end{tabular}

* shows significance at $1 \%$ and the numbers in parentheses are standard deviations 


\subsection{Analysis of Volatility and Conditional Variance}

In the first step, the univariate GARCH (1.1) is specified for each of the returns. For this purpose, the conditional variance is modeled in three models: GARCH, EGARCH ${ }^{1}$, and GJR ${ }^{2}$. By comparing the Akaike and Schwartz criteria and amount of likelihood, the selected model is GJR. Greater long-run $(\mathrm{GARCH})$ effect than the short-run (ARCH) effect is observed for the indices, which implies strong long-run volatility. In the second part of the Table, the Ljung-Box test statistic for standard errors and square of standard errors is reported, which shows that the hypothesis of serial non-correlation in both of them is rejected.

To investigate whether the conditional correlation is constant or changes over time, multivariate GARCH (1.1) models are estimated in the second step. For this purpose, the standard errors of the selected models in the previous step are extracted, and then CCC and DCC models are estimated. Table (5) shows the results of the CCC model diagnostic test. The results of the Ljungxbox test shows that the standard errors and their variances are not serial correlated, and the selected model has well defined the data.

In the second part of Table (6), the results of the conditional correlation stability test are reported.

The results suggest that the hypothesis of conditional correlation stability is rejected over time; therefore, the DCC model estimated. The results of the DCC model are reported in Table (6).

The results are significant and indicate the dynamic correlation between stock market return and dollar return. Based on the dynamic conditional variance, two markets follow the same behavior in the estimated conditional variance, which indicates the spillover effect between stock and dollar returns.

\footnotetext{
${ }^{1}$ The EGARCH model was proposed by Nelson 1991. In this model, conditional variance is modeled as follows. $\ln \sigma_{t}^{2}=\alpha_{0}+\alpha_{1} \frac{\left|u_{t-1}\right|}{\sqrt{\sigma_{t-1}^{2}}}+\beta \ln \sigma_{t-1}^{2}+\gamma \frac{u_{t-1}}{\sqrt{\sigma_{t-1}^{2}}}$. This model has several advantages. First, in this model, the dependent variable $\left(\sigma_{t}^{2}\right)$ is logarithmic, so the coefficients of the variables on the right can be positive or negative, which in any case will be positive for $\sigma_{t}^{2}$, and there is no need to apply non-negative constraints on the coefficients. Second, in this model, the effect of asymmetric shocks is also considered because $\gamma$ is the $u_{t-1}$ coefficient, which can be positive or negative.

2 The GIR model is the simplest type of asymmetrical GARCH model. In this model, conditional variance is modeled as follows: $\sigma_{t}^{2}=\alpha_{0}+\alpha_{1} u_{t-1}^{2}+\beta \sigma_{t-1}^{2}+\gamma u_{t-1}^{2} I_{t-1}$. If $\gamma$ is not significant, the effect of shocks on variability is the same for the case in which the negative shock or positive shock is applied. But if $\gamma$ is significant, the model is asymmetric and the effect of positive and negative shocks cannot be the same.
} 
The dynamic conditional variances diagram and their conditional correlation in the DCC model are shown in Figure (2).

Table 4

GARCH parameter estimates

\begin{tabular}{lllllll}
\hline \multicolumn{3}{c}{ Stock return } & \multicolumn{4}{c}{ Dollar return } \\
\hline $\mathbf{u}$ & GARCH & EGARCH & GJR & GARCH & EGARCH & GJR \\
$\boldsymbol{\alpha}$ & 0.000299 & 0.00038 & 0.000395 & 0.000135 & 0.0004 & 0.000436 \\
$\boldsymbol{\beta}$ & 0.2138 & 0.2133 & 0.2393 & 0.238 & 0.4651 & 0.3741 \\
$\boldsymbol{\gamma}$ & 0.7928 & 0.7922 & 0.8198 & 0.8197 & 0.8192 & 0.8204 \\
LogL. & 4187.2 & 4202.4 & 4204.2 & 3963.3 & 3986.4 & 4002.6 \\
AIC & -7.12 & -7.14 & -7.15 & -6.75 & -6.78 & -6.80 \\
SIC & -7.10 & -7.13 & -7.138 & -6.74 & -6.77 & -6.79 \\
\hline DIAGNOSTICS & & & & & \\
\hline Q(12) & 218.55 & 216.5 & 227.8 & 19.55 & 18.08 & 18.54 \\
P-value & $(0.041)$ & $(0.061)$ & $(0.072)$ & $(0.0759)$ & $(0.1131)$ & $(0.1002)$ \\
Q $(12)$ & 9.41 & 11.34 & 13.91 & 13.21 & 10.56 & 6.5 \\
p-value & $(0.4006)$ & $(0.2527)$ & $(0.1257)$ & $(0.1533)$ & $(0.3068)$ & $(0.7731)$ \\
\hline
\end{tabular}

Table 5

CCC diagnostic

\begin{tabular}{|c|c|c|}
\hline LogL. $=-3284.4$ & $\mathrm{AIC}=5.595$ & SIC $=5.599$ \\
\hline \multicolumn{3}{|c|}{ Diagnostic test for standardized residuals } \\
\hline & Stock return & Dollar return \\
\hline $\begin{array}{c}Q(12) \\
p-\text { value }\end{array}$ & $\begin{array}{l}233.411 \\
(0.00)\end{array}$ & $\begin{array}{l}16.747 \\
(0.1593)\end{array}$ \\
\hline $\begin{array}{c}Q_{s}(12) \\
p-\text { value }\end{array}$ & $\begin{array}{l}21.977 \\
(0.0377)\end{array}$ & $\begin{array}{l}15.64 \\
(0.2080)\end{array}$ \\
\hline \multicolumn{3}{|c|}{$\begin{array}{l}\text { Constant conditional correlation test } \\
\text { LM test }=9.23 \\
(0.0024)\end{array}$} \\
\hline $\begin{array}{l}\text { Dynamic conditiona } \\
E-S \text { test }=85.5 \\
(0.4391)\end{array}$ & & \\
\hline
\end{tabular}

Numbers in () show p-values; E-S test is Engle and Sheppard test 
Table 6

DCC estimates

\begin{tabular}{|c|c|c|}
\hline & & $\theta$ \\
\hline coefficient & \multicolumn{2}{|l|}{$0.3373^{*}$} \\
\hline $\mathrm{p}$-value & \multicolumn{2}{|l|}{$(0.0345)$} \\
\hline Std.error & \multicolumn{2}{|l|}{0.1593} \\
\hline t-stat & \multicolumn{2}{|l|}{2.117} \\
\hline Log.L & \multicolumn{2}{|l|}{-3062.43} \\
\hline AIC & \multicolumn{2}{|l|}{1970.56} \\
\hline \multicolumn{3}{|c|}{ Diagnostic test for standardized residuals. } \\
\hline & Stock return & Dollar return \\
\hline $\begin{array}{c}Q(12) \\
p-\text { value }\end{array}$ & $\begin{array}{l}220.199 \\
(0.00)\end{array}$ & $\begin{array}{l}171.19 \\
(0.0844)\end{array}$ \\
\hline $\begin{array}{c}Q_{s}(12) \\
p-\text { value }\end{array}$ & $\begin{array}{l}16.54 \\
(0.1677)\end{array}$ & $\begin{array}{l}14.421 \\
(0.2746)\end{array}$ \\
\hline
\end{tabular}
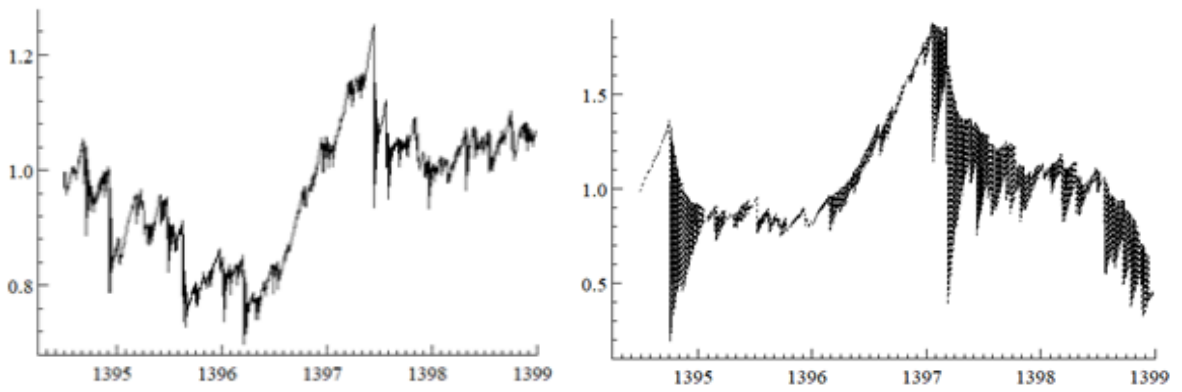

Figure 2. Time-Varying Conditional Variances (Left Column) and Conditional Correlations (Right Column) From DCC Model.

Following an increase in sanctions in 1397, increasing in dollar return sharply transferred to stock return. In Figure (3), the dynamic conditional correlation between stock and the dollar returns of the DCC model is shown. The horizontal line shows the constant conditional correlation that is assumed to be the CCC model. As can be seen, the conditional correlation fluctuates completely, and the assumption of its stability is rejected. 


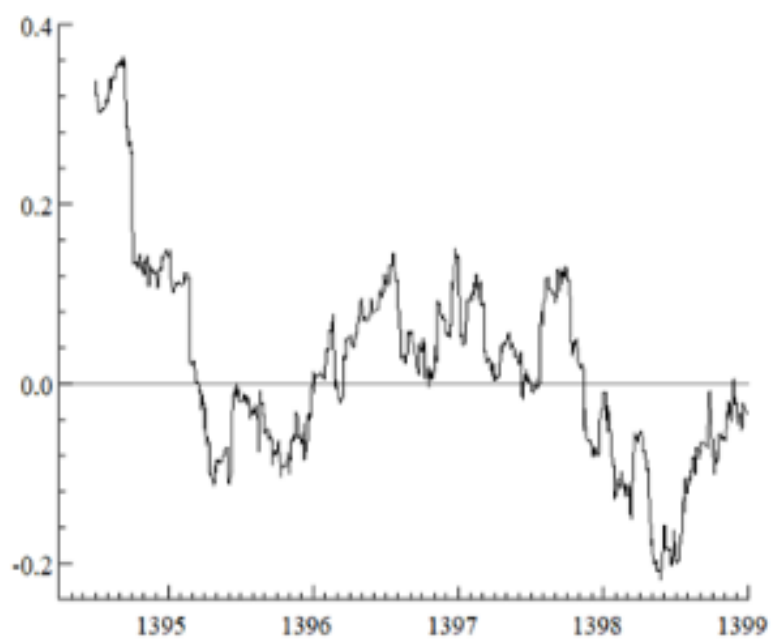

Figure 3. Dynamic Conditional Correlation between Stock and the Dollar Returns of DCC Model.

\section{Conclusion}

This article examines mean and volatility transmission among dollar return, the global economy, and the local financial market. The main contribution of the study is to capture both mean and variance spillover among these markets. For this purpose, using the daily data of 1394-1398, CCC, and DCC models from the family of GARCH models were estimated. The conditional correlation stability test was not confirmed, so the DCC model was selected for estimation. Mean conditional results and conditional correlation are both statistically and economically significant. Mean conditional results show that stock returns react negatively to dollar returns. The results show a substitution between dollar return and stock return among economic agents. For the global economy, the stock market return is declining, with fluctuations in the global economy index. Still, for the dollar, the relationship is reversed, and with fluctuations in the global economy index, dollar returns are rising. The results of the conditional correlation also show a robust conditional correlation between the returns of the two markets and confirm the spillover effect of volatility between the two markets. The application of the results can be summarized in the macro field.

Given the stocks of different companies in the stock market and over-thecounter market, identifying how the capital market and stock prices are affected by currency fluctuations is important for government, managers, and 
shareholders that can play a decisive role in strategic decisions. Also, spillover mechanisms in stock price management are important for companies. Having information about the impact of exchange rate spillover can be used in strategy selection, diversification, and scenario analysis to reduce investment risk in various projects in the form of portfolio adjustments.

\section{References}

Abounoori, S., Abdolahi, M. R., \& Hamza, M. (2013). Dynamic Relationship between Exchange Rate and Tehran Stock Exchange Index Using Multivariate GARCH Model. Iranian Journal of Trade Studies, 17(65), 65-86.

Bollerslev, T. (1986). Generalized Autoregressive Conditional Heteroskedasticity. Journal of Econometrics, 31(3), 307-327.

Bollerslev, T., \& Wooldridge, J. M. (1992). Quasi-Maximum Likelihood Estimation and Inference in Dynamic Models with Time-Varying Covariances. Econom. Rev., 11(2), 143e172.

Botshekan, M. H., Sadeghi Shahedani, M., Salimi, M. J., \& Mohseni, H. (1396). Spillover of Fluctuations on the Stock Exchange. Quarterly Journal of Economic Research and Policy, No. 25, 165-189.

Bozma, G., \& Başar, S. (2018). Analyzing Volatility Transmissions between Stock Markets of Turkey, Romania, Poland, Hungary and Ukraine Using M-GARCH Model. Hacettepe Üniversitesi İktisadi ve İdari Bilimler Fakültesi Dergisi, 36(4), $1-15$.

Diebold, E., \& Yilmaz, K. (2012). Better to Give Than to Receive: Predictive Directional Measurement of Volatility Spillovers. Int. J. Forecast. 57-66.

Ely, R. A. (2015). Volatility Spillovers and the Risk-Return Relation between Stock and Foreign Exchange Markets in Brazil. Latin American Business Review, 16(4), 305-325.

Engle, R. F. (1982). Autoregressive Conditional Heteroscedasticity with Estimates of the Variance of United Kingdom Inflation. Econometrica, 50(4), 987-1007.

Engle, R. F., \& Kroner, K. (1995). Multivariate Simultaneous Generalized ARCH, Econometric Theory, 11(1), 122-150.

Granger, C. (1969). Investigating Causal Relations by Econometric Models and Cross-spectral Methods. Cross Spectral Method Econometrica, 424-438.

Heidari, H., \& Bashiri, S. (2012). Investigating the Relationship between Real Exchange Rate Uncertainty and Stock Price Index in Tehran Stock Exchange Using VAR-GARCH Models. Journal of Economic Modeling Research, 3(9), 7193.

Kang, S., Eom, C., \& Ok, S. (2017). Dynamic Volatility Spillovers across Emerging CDS Markets. In: $11^{\text {th }}$ Multidisciplinary Academic Conference, (S. 196-202). Prague. 
Nahidi, M. \& Nikbakht (2010). Study the Effect of Volatility of Real Exchange Rate on Dividend and Price Index (TEDPIX) in Tehran Stock Exchange, Journal of Securities Exchange, 3(11), 43-59.

Raghavan, M. V., \& Dark, J. (2008). Return and volatility spillovers between the foreign exchange market and the Australian All Ordinaries Index. The IUP Journal of Applied Finance, 14(1), 41-48.

Sims, C. (1980). Macroeconomics and Reality. Econometrica, 48, 1-48.

Sun, T., \& Zhang, X., (2009). Spillover of the U.S. Subprime Financial Turmoil to Mainland China and Hong Kong, SAR: Evidence from Stock Markets. Washington, DC: IMF Working Paper 09/166.

Taghavi, M., \& Biabani, S. (2003). Effects of the Free-Market Exchange Rate Change and Future Cash Flow on the Value of Shares of Public Joint-Stock Companies Listed on the Tehran Stock Exchange. Journal of Economic Research, 3(1), 13 38.

Vardar, G., \& Aksoy, G, E. (2008). Effects of Interest and Exchange Rate on Volatility and Return of Sector Price Indices at the Istanbul Stock Exchange. Eur. J. Econ. Finance Adm. Sci. 126-135. 